Appeared in: Doluca, H., Holzner, B. \& Wagner, M. (2019) Corporate Sustainability and Environmental Innovations: Practical Implications From a Cross-Country Analysis Over 15 Years. IEEE Engineering Management Review, 47(2), 115-122, DOI:10.1109/EMR.2019.2903007

\title{
Corporate Sustainability and Environmental Innovations: Practical Implications from a Cross-Country Analysis Over 15 Years
}

\author{
Hüseyin DOLUCA \\ Benedikt HOLZNER \\ Marcus WAGNER \\ Chair for Management, Innovation and International Business, Augsburg University, 86159 Augsburg, Germany
}

\begin{abstract}
Sustainability and environmental related innovation activities are important for the present and for the future. These innovations occur throughout the world and in different contexts. Manufacturing related organization may approach these activities from different perspectives. The question we raise is whether country-related differences, in this case, between Germany and the United Kingdom exist and how they changed over time. Using survey information, we find that sustainability and environmental innovation activities have increased greatly. What has become more popular has shifted over the years. We find some differences in the countries and the types of initiatives. We also find small and large firms may focus on different initiatives. These results are of interest to managers and policy makers; we point to some possible practical takeaways from our study.
\end{abstract}

Key words: Corporate sustainability, environmental innovation, environmental management system

\section{INTRODUCTION}

The World Commission on Environment and Development [1] has supported shifts in governmental policies as well as corporate decision making towards organizational sustainability. Meeting financial, ecological and social goals has been the mantra of forward thinking organizations. This mantra and drive has resulted in an increase of firm-level environmental and sustainability innovations. 
Empirical research has analysed the environmental innovation and corporate sustainability [2-4]; but so far only over shorter time periods. We ask the question of what has happened in the corporate sustainability and environmental innovation realm over longer periods of time. We also want to determine whether country-, time- and industry-specific differences exist. These are important questions for ecologically influenced companies and entrepreneurs seeking direction and location for their markets and organizations.

This exploratory analysis aims at addressing these questions. We evaluate the historical development of corporate sustainability and environmental innovation between 2001 and 2016 in two different countries. We provide additional insights on why these findings are helpful and provide some advice to managers, regulators, as well as consultants and other industrial professionals.

A little background on the data. We tap into a unique dataset containing manufacturing firms in Germany and the United Kingdom (UK) from 2001 and 2016. This dataset allows us to further delve into how various sized organizations-small, medium-sized and large firms-are acting during this time period.

We find that environmental activities and implementation of environmental management systems (EMS) increased from 2001 to 2016. But, interestingly, which we detail below, some environmental and sustainable innovation activities have decreased during this period. Industry and country effects play a very important role regarding sustainability and environmental innovation activities. Except for operational sustainability activities, sustainability and environmental innovation activities are more widely diffused in Germany than in the United Kingdom. But, the UK also utilizes some activities more intensively when compared to Germany. We discuss what this may mean to practitioners.

We touch on how others' studies and works provide some background for our study. A more detailed exposition and discussion of our results are then presented. We then provide some implications and recommendations for managers, policy makers and researchers.

\section{BACKGROUND}

Corporate sustainability, as part of the 'triple-bottom-line' concept, includes activities related to economic, environmental and social aspects. The goal is to realize sustainable development for society overall.

Environmental innovation may have a narrower definition than corporate sustainability. For our purpose, we use the definition of environmental innovation as novel "products and processes 
applied or introduced to contribute to a reduction of environmental burdens or to ecologically specified sustainability targets" ([5]: p. 322).

Corporate sustainability and environmental innovation can be dependent on several factors-firm size is one. Interestingly, it is not always the case that large firms, with their resources, are more environmentally innovative. In fact, large firms less likely undertake many risky and radical innovations [6]. We revisit this question in in the next section of this paper.

Environmental innovations do not occur in a vacuum. The implementation of EMS depends on country-specific conditions and its existence plays a role in firm-level innovation activities [7-8].

Also, not all environmental innovations are equal. For example, in our previous studies we found relationships between environmental process innovations and EMS, but not between environmental product innovations and EMS. Rather, activities beyond those required in EMS, such as eco-labelling or environmental R\&D cooperation are associated with environmental product innovation [2-3].

We use a unique dataset - the European Sustainability Management Panel-to compare corporate sustainability and different environmental innovations over a period of 15 years and in two countries. The cross-country comparison allows us to identify country-based strengths and weaknesses with regard to corporate sustainability and environmental innovations. Additionally, information about the status quo and insights on recent trends are provided. A brief description of how the dataset was generated appears in Box 1. Next provide some analyses on corporate sustainability with identified practical implications to regulators, policy makers and managers. Firm size and different types of innovations in the context of social sustainability are also studied as part of this.

\section{Box 1: Description of dataset generation}

Our dataset is based on data gathered in 2001 (mostly in the context of the European Business Environment Barometer, henceforth EBEB) and 2016 (as part of the European Sustainability Management Barometer, henceforth ESMB). Both, the ESMB as well as the EBEB survey were conducted among manufacturing companies by using the same questions in 2001 and 2016, thus providing the unique possibility to empirically compare the development of sustainability over a period of 15 years in high detail. The questionnaires have been send out to random samples of manufacturing firms in Germany and the UK with the final dataset containing 783 observations of which 221 are from the UK. 


\section{ANALYSIS}

We rely on frequency counts to assess the data. The differences between Germany and the UK are presented by considering corporate sustainability and environmental innovation from 2001 until 2016. We particularly evaluate technological and managerial environmental management activities. In the next section, we compare internal and external social sustainability activities between the two countries.

\section{A. Environmental sustainability}

In the next three subsections, operational and managerial environmental, and environmental-related cooperation activities are examined; each grouping to a subsection. This evaluation is over the 15year time period between 2001 and 2016. We also look at how adoption of these activities evolved in Germany and the UK.

\section{Operational environmental activities}

One of the major questions we asked companies in the survey was about 19 operational activities aimed at improving firm's environmental performance. We asked what was adopted during a three year window before the year 2016, and before the year 2001, respectively.

As can be observed in Figure 1, 16 activities appear in both 2001 and 2016; these activities also occur in both countries. Three operational activities biodiversity conservation, biodiversity restoration and emissions offsetting were added in 2016 and do not appear in the 2001 results. It is not surprising that these three added activities, although important, have yet to be adopted by organizations in either country context.

We do observe a number of cross- country differences. These differences appear in the most and least adopted operational activities. In Germany, substitution of hazardous products increased the most from 2001 to 2016 (by 30\%). Substitution has become, along with reduction of waste, one of the most implemented activities in 2016.

Interestingly, within the 15-year time span recycling activities did not increase for German firms. No activity decreased over time. In fact, nine activities increased adoption rates by more than $25 \%$.

British firms were more likely adopt recycling activities in recent years. The three most adopted activities in 2016 in the UK include material recycling (95\%), packaging recycling (81\%) and product recycling (76\%). Overall, these results point to UK firms focusing on recycling while German firms Germany focus on efficient production activities.

Of special interest are activities corresponding to process-clean technologies in the production process-and product-green design of new products-innovation. 
Product and process innovation activities have similar results to other operational activities, especially when considering country trends over time. In 2001, and in 2016, a relatively larger percentage of German firms undertook product and process environmental innovations, when compared to UK firms.

Only 26\% (38\%) of firms undertook product (process) innovations in 2001 UK, while in Germany 42\% (53\%) did so fifteen years ago. In 2016 38\% (57\%) and 50\% (63\%) of the UK and German firms, respectively, did undertake product (process) innovations. In both cases, the trend had a similar increase.

Operational sustainability activities are on average more often adopted by larger firms than by small and medium-sized firms (SME). In Germany small firms increasingly implemented product recycling and package reduction activities. Medium-sized firms adopted more operational activities in general, and matched 2016 large firm adoption rates.

Even though SMEs increased their adoption rates within the 15 -year period, product and process innovation activities are relatively more likely undertook by larger firms.

[Insert Figure 1 about here]

\section{Managerial environmental activities}

The survey asked respondents which managerial environmental activities they have undertaken in both survey rounds. Figure 2 summarizes the percentage of firms in the respective year and country having implemented specific managerial activities.

The average German or UK firm has adopted a greater number of managerial than operational activities. In Germany most firms have adopted two-thirds of the managerial activities. In UK on average only about half of the activities were adopted. The average German firm adopts more managerial activities than the average UK firm.

In Germany for both 2001 and 2016 assigning clear responsibilities (74 and 90\%, respectively) and procedures to handle legal requirements ( 57 and $84 \%$, respectively) are the most often implemented managerial environmental activities. Procedures to handle legal requirements are the most popularly implemented managerial activities in the UK for both years (70\% and $95 \%$, respectively). Written environmental policy, with adoption rates of 69\% (in 2001) and 90\% (in 2016), is the second largest managerial practice adopted in the UK. 
In both countries manufacturing firms rarely benchmark their own environmental performance with other companies and make less effort to do market research on green products; these activities represent the least adopted practices.

Eco-label activity adoptions vary significantly between German and UK firms. German firms significantly increased eco-label adoption levels between 2001 (16\%) to 2016 (44\%). Alternatively, UK firms only increased adoption rates from 14\% in 2001 to $19 \%$ in 2016.

Reviews of EMS efficiency, use of environmental performance indicators, and placing demands on suppliers to take environmental activities are adopted at greater levels by German firms in 2016. British firms are more likely to incorporate environmental data in their annual reports.

[Insert Figure 2 about here]

Analogous to operational activities adoption, all size firms adopted a greater number of managerial activities in 2016 than they did in 2001. SMEs adoption rates significantly lag behind large firm adoption rates in 2001. In 2016 both medium-sized and small firms increased their managerial activities nearly keeping pace the high adoption levels of large sized firms. This finding implies that over time firm competitive differentiation from managerial activities adoption is now more difficult. In 2016, as in 2001, corporate sustainability and environmental innovation activities are found to increase with company size in both countries. The likely reason is greater availability of resources in large firms (see Figure 3); but they may also be more visible and have greater pressures to adopt these activities.

[Insert Figure 3 about here]

\section{Environmentally-related cooperation activities}

Cooperation with external partners leads to more innovative firms. This result is especially true when cooperating with suppliers and customers [9]. Environmental innovation also benefits from customer and supplier cooperation.

Survey respondents were also asked if they cooperated on environmentally oriented product planning or development processes with suppliers or customers over last three years. German firms 
had greater cooperation in 2016 (79\%) when compared to 2001 (62\%). German firms (79\%) cooperate with suppliers and consumers more often than UK firms (70\%).

Overall, environmental innovation cooperation has become more important and common over the past 15 years.

\section{B. Internal and external social sustainability}

In addition to managerial and operational environmental management activities, firms also undertake activities related to social issues.

This subsection focuses on internal and external activity differences when organizations address social sustainability that were surveyed in 2016 only. Respondents answered questions on 17 and 21 activities related to internal and external social activities, respectively.

UK and Germany do not differ on the most implemented activities (see Figure 4). Health protection, general education programmes for employees and employee suggestion schemes are the most often implemented internal social sustainability activities for both country samples.

There do exist country-specific differences in the adoption levels. In Germany approximately $90 \%$ of firms adopt these activities; only about $75 \%$ do so in the UK.

British firms focus on support of gender diversity, individual work time models, flexible work place design and childcare of employees, with each of these social activities having at least $50 \%$ adoption rates. German firms also have these high rates, except for childcare support.

In Germany, social benefits and qualification activities for jobs are implemented by more than $50 \%$ of firms; these activities are less adopted in the UK. A similar gap is observed for the social standard "Recommendation 146" of the International Labour Organisation (ILO), which is adopted by $51 \%$ of German and only $33 \%$ of UK firms.

The lowest adoption rates for internal social activities include sustainability balanced scorecards and UN Global Compact membership. A relatively small percentage of German and UK firms implemented the European Foundation for Quality Management (EFQM) model to achieve societal and employee-related welfare goals, respectively. Only $10 \%$ of German and no UK firms have adopted the ISO 26000 guidelines for social responsibility.

In summary, while the top internal social activities are the same in the UK and Germany, country differences still exist on the remaining internal social activities. 
[Insert Figure 4 about here]

External social sustainability adoption rates are presented in Figure 5. The external social sustainability activity most often implemented in both countries is offering apprenticeship positions. As in the case for internal social activities, the adoption rate for this external social activity was higher in Germany than the UK.

There exist differences regarding various individual external social sustainability activities. Fair trade relationships ( $87 \%$ versus $41 \%$ ) and sponsoring of sports and cultural events (76\% versus $35 \%$ ) are more likely to be adopted in Germany than in the UK.

In Germany and the UK, the least implemented activities include the fair trade certification of own products ( $13 \%$ and $14 \%$, respectively) and the adoption of the Social Accountability 8000 standardless than $15 \%$ of firms in both countries.

[Insert Figure 5 about here]

\section{IMPLICATIONS FOR MANAGERS AND POLICY MAKERS}

We now make a number of managerial observations and recommendations for practitioners, policy makers and researchers.

One main finding is that within the 15-year time span the average manufacturing firm did increase its environmental efforts in both, Germany and the UK. Nevertheless, some environmental activities are currently less widely diffused than they were 2001. While managerial activities are and were more relevant in Germany, operational activities have become more popular in the UK in 2016. Also, while social activities are very widespread across firms in the UK and Germany, certain social activities have especially become standards in Germany. There is still potential to improve the social performance.

Why are these results important?

Firms and countries can benchmark their own sustainability performance within their own as well as compared to other manufacturing industries. A question for managers, is how well does your organization compare to the adoption of these initiatives? As can be seen, competitive differentiation on these measures is becoming more difficult. Yet, organizations, both small and large need to see that the bar of the 'status quo' has increased. 
Even if your organization is not in Germany or the UK, they are likely to be competing in some of the same markets. Does your organization measure up on these activities and environmental innovations? In the past this was a way to differentiate against competitors. Nowadays it is a must to adopt sustainability-related activities. Not adopting these innovations may result in competitive disadvantages.

Although differentiation based on sustainability on a broad level seems difficult at first glance, this may not be true for SME, for example. They can learn from knowledge already generated in larger firms and from exemplary adoptions that exist. This shows that the learning and resource requirement curves have lower barriers today, which results in more catch-up opportunities.

As the implementation of some environmental activities can at least partly be attributed to countryspecific regulations, firms still have room to differentiate from competitors by implementing nonregulated environmental activities. As can be seen, some of the less implemented programs provide some opportunity for competitive advantages. Emergent standards are some of these. Companies who wish to stay ahead of the curve may consider these and other less adopted activities and innovations. When doing so they can again benefit from knowledge and experience available in other countries.

Policy makers are interested in a better understanding of the variation between individual firms with regard to environmentally related and socially beneficial innovation activities. These findings can substantiate and ameliorate policy initiatives. If programs have worked, they may no longer need regulatory enforcement and new programs can be promoted. Care should be taken, though to make sure that gains are not lost.

Incentives in favour of those activities being less adopted but highly relevant for achieving sustainable development can be identified with these exploratory results. Some are clearly lagging and the regulatory and incentive structures can shift.

Finally, our findings also have implications for researchers. Analyses on corporate sustainability and environmental innovation should be considering the time-dependent differences as well as the spatial scope of the data gathered. Moreover, our findings suggest that generalising results from an analysis being based on one industrialized country to another industrialized country is not always possible partly because of regulatory differences. Generalisations should be considered with heightened care.

To conclude, it is encouraging to see increasing adoption of these socially and environmentally sound organizational practices. But, whether they are working needs to be further evaluated. That is, are 
the outcomes actual better sustainable development performance? These issues are left for future studies. 


\section{REFERENCES}

[1] World Commission on Environment and Development, Our Common Future. Oxford, UK: Oxford University Press, 1987.

[2] M. Wagner, "On the relationship between environmental management, environmental innovation and patenting: Evidence from German manufacturing firms," Research Policy, vol. 36, no. 10, pp. 1587-1602, Dec. 2007.

[3] M. Wagner, "Empirical influence of environmental management on innovation: evidence from Europe," Ecological Economics, vol. 66, no. 2-3, pp. 392-402, Jun. 2008.

[4] J. Horbach, C. Rammer, and K. Rennings, "Determinants of Eco-innovations by Type of Environmental Impact - The Role of Regulatory Push/Pull, Technology Push and Market Pull," Ecological Economics, vol. 78, pp. 112-122, Jun. 2012.

[5] K. Rennings, "Redefining innovation-eco-innovation research and the contribution from ecological economics," Ecological Economics, vol. 32, no. 2, pp. 319-332, Feb. 2000.

[6] P. Almeida, and B. Kogut, "The exploration of technological diversity and geographic localization in innovation: Start-up firms in the semiconductor industry," Small Business Economics, vol. 9, no. 1, pp. 21-31, Feb. 1997.

[7] M. A. Delmas and M. J. Montes-Sancho, "An institutional perspective on the diffusion of international management system standards: The case of the environmental management standard ISO 14001," Business Ethics Quarterly, vol. 21, no. 1, pp. 103-132, Jan. 2011.

[8] J. Horbach, "Determinants of Environmental Innovation - New Evidence from German Panel Data Sources," Research Policy, vol. 37, no. 1, pp. 163-173, Feb. 2008.

[9] R. Belderbos, M. Carree, and B. Lokshin, “Cooperative R\&D and firm performance," Research Policy, vol. 33, no. 10, pp. 1477-1492, Dec. 2004.

Hüseyin Doluca is an Assistant Professor with the Chair for Innovation and International Business, Augsburg University, Augsburg, Germany. His research and teaching focuses on topics in the fields of innovation, entrepreneurship, sustainability, SMEs, and family firms.

Benedikt Holzner received the B.S. and M.S. degrees in law and business studies from the University of Augsburg's Law School, Augsburg, Germany. Currently, he is a Research Fellow and a Doctoral Student with the Chair for Innovation and International Management, Augsburg University, Augsburg, Germany. His research interests include sustainable innovations and business environment factors.

Marcus Wagner is a Professor of Management, Innovation and International Business with Augsburg University, Augsburg, Germany, and an Associate Member of the Bureau d'Economie Théorique et Appliqueé, Strasbourg, France, where he was a Marie Curie Fellow. His research focuses on innovation, global sustainability, and strategic management, and has been published, inter alia, in Journal of Business Venturing, Long Range Planning, and Research Policy. 
Figures

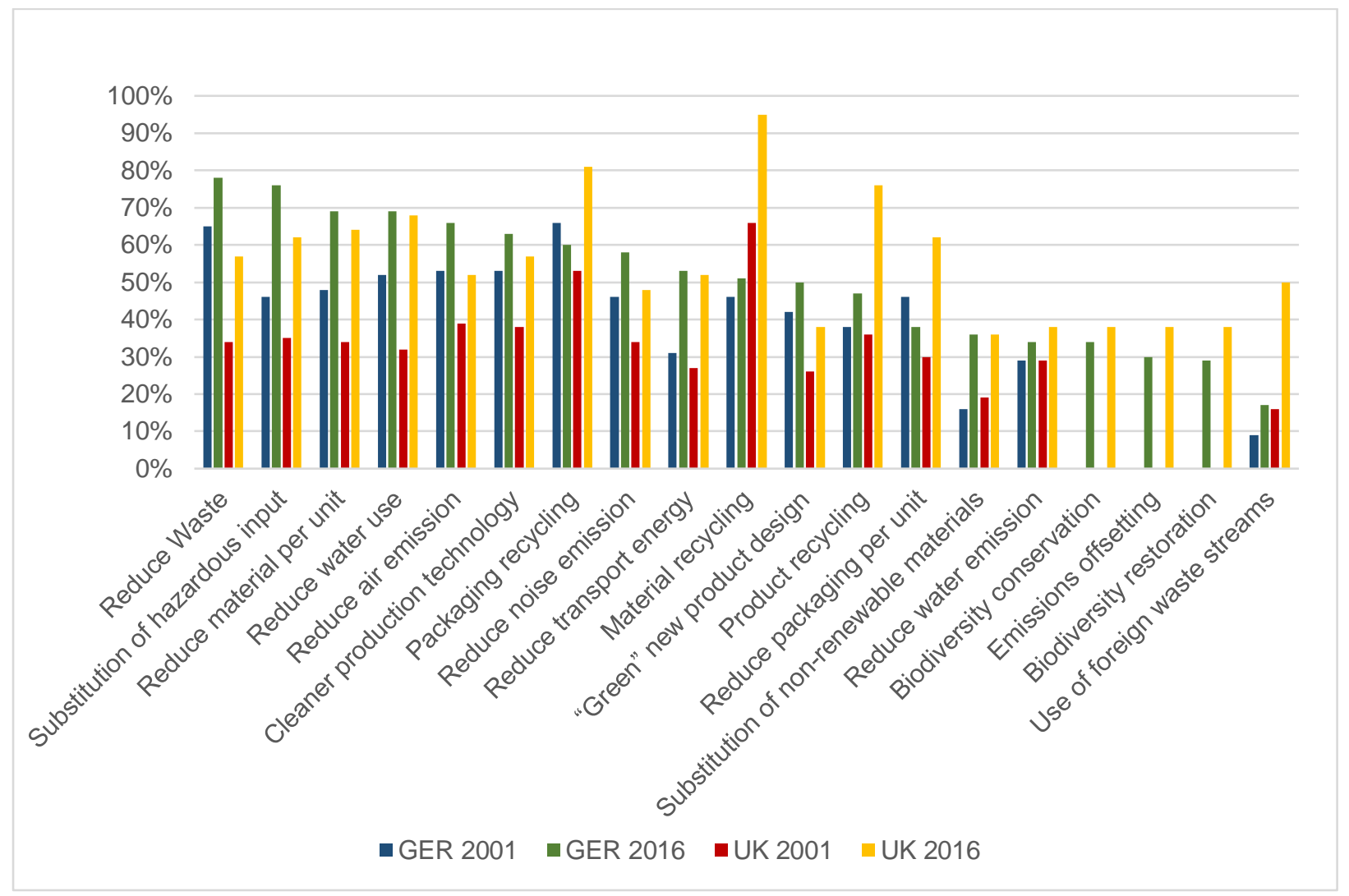

Figure 1: Operational activities by country and year. 


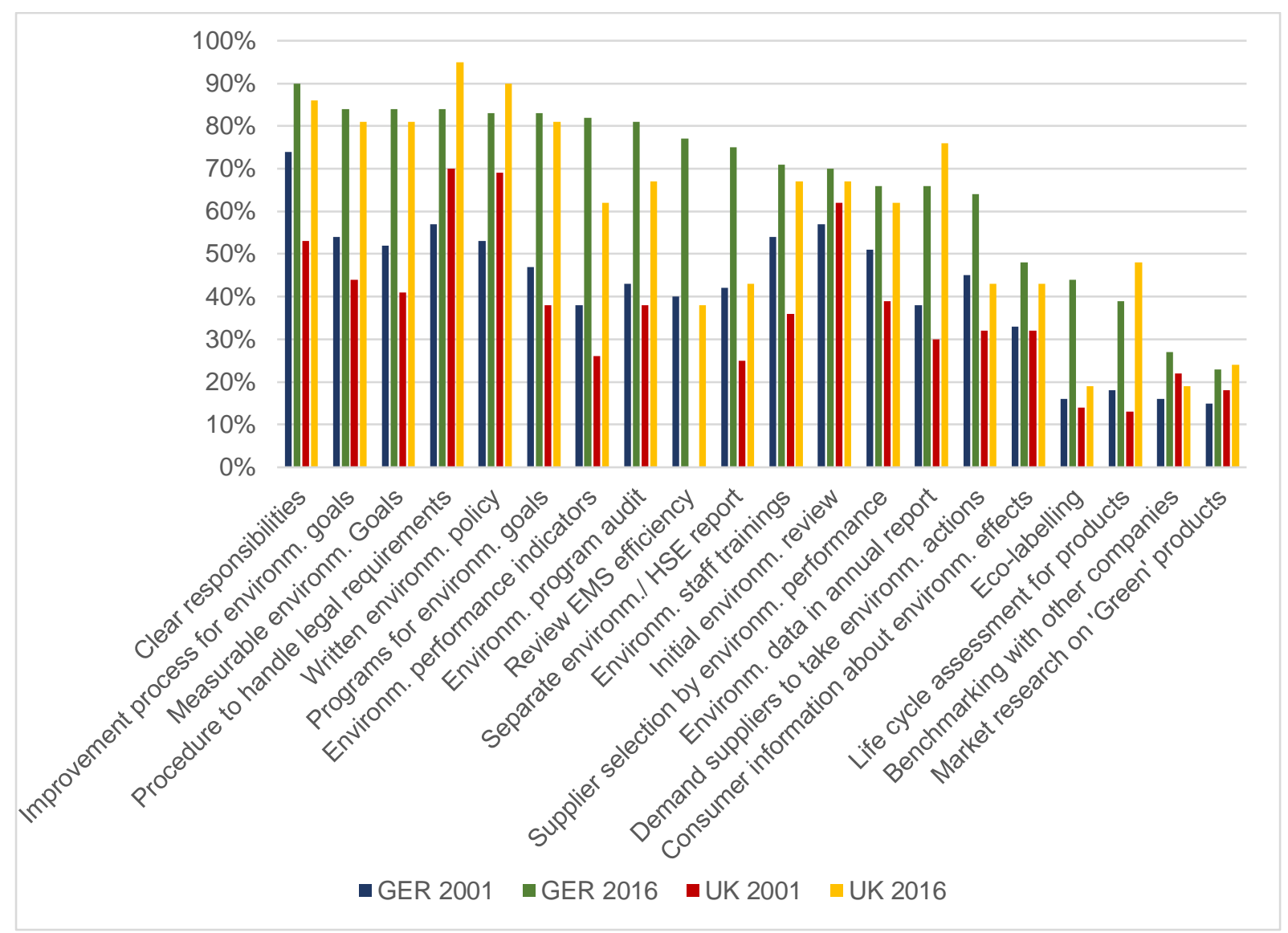

Figure 2: Managerial activities by country and year.

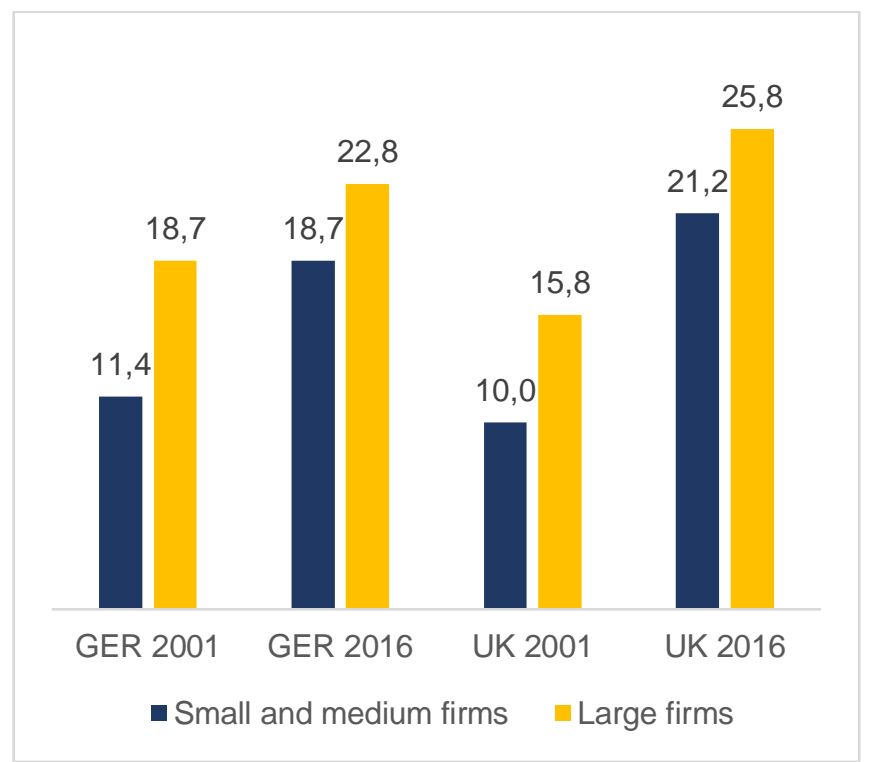

Figure 3: Average of managerial and operational activities. 


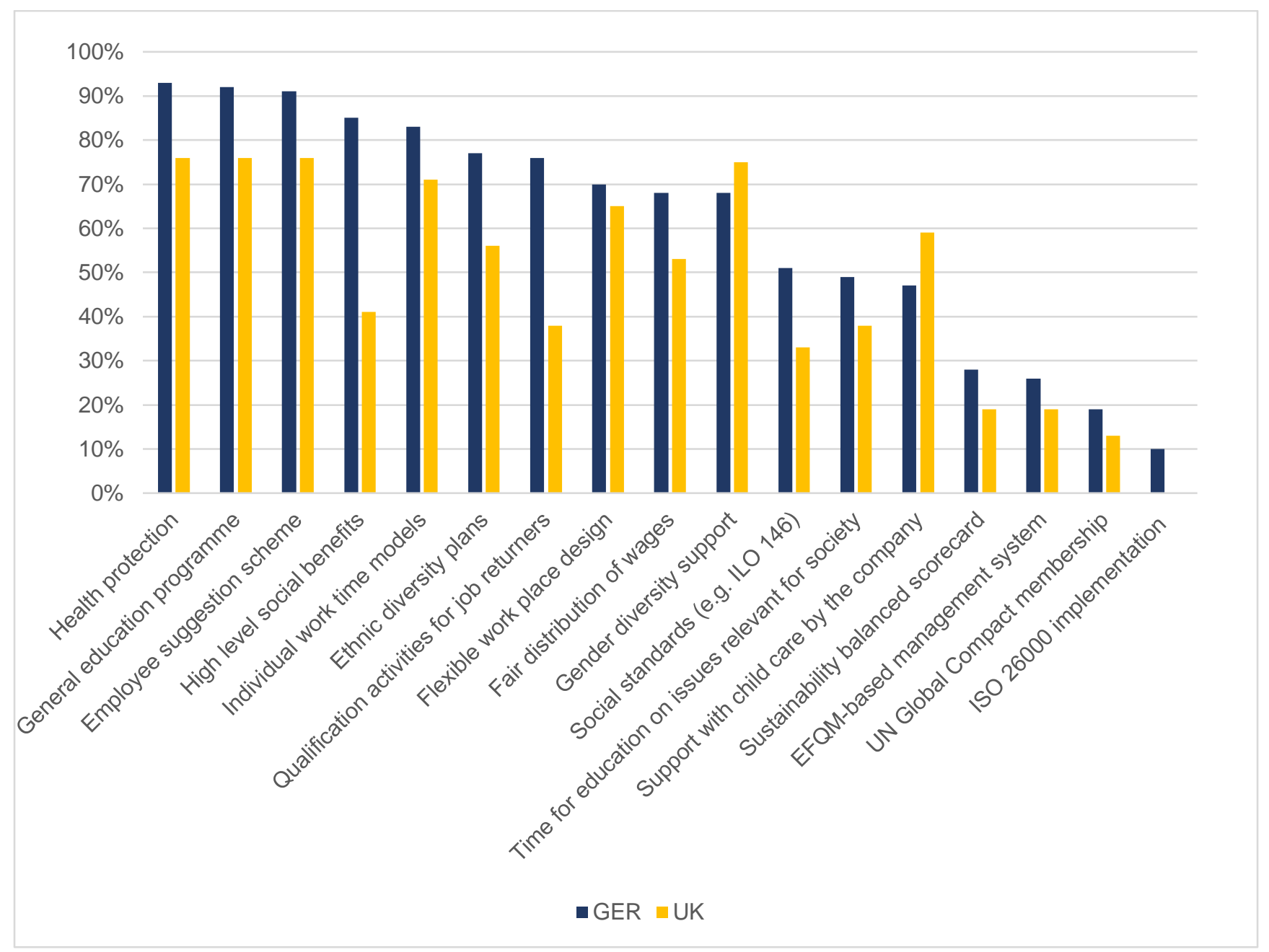

Figure 4: Internal social sustainability activities. 


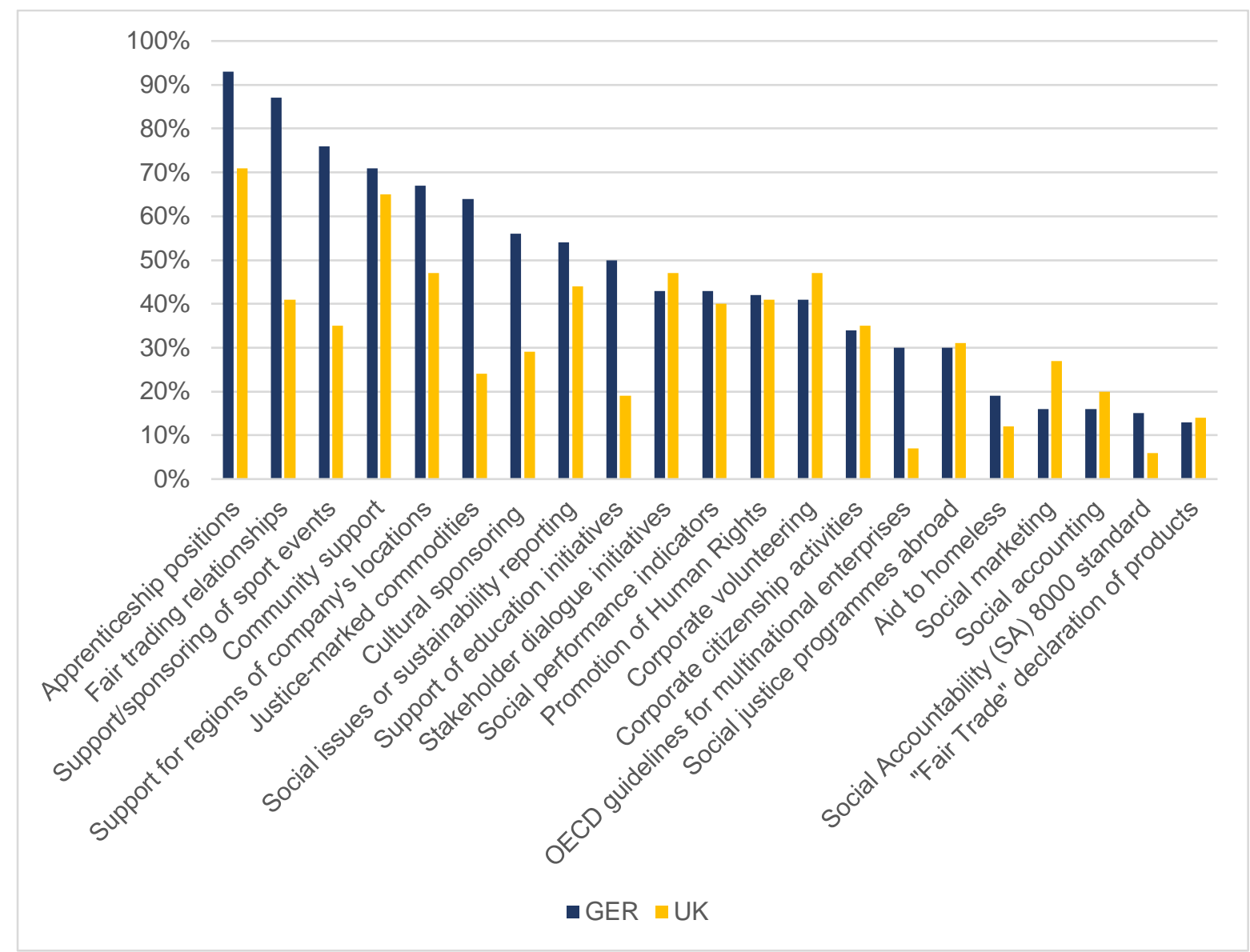

Figure 5: External social sustainability activities. 